Perspective

\title{
Preservatives in our food: part I
}

\section{Introduction}

Preservation has a significant role in the food industries application activates, and the food science researches. It is not, somehow easy to find comprehensive articles containing extensive information in respect of food preservation materials.

I thought it is a good idea to shed light on the essential facts, in a series of simple attractive articles, whose title will be the «Preservatives in Our Food" and hope to be useful and of value to all.

\section{Food and microorganisms}

Food quality is one of the important criteria that require careful attention and constant observation, as it can be directly affected by the microbial activities and the microorganism's growth, or by the natural food chemical reactions.

The biological processes that lead to food spoilage by microorganisms require the flowing conditions:

\section{Spoilage causes availability}

Mainly, we are talking about the microorganisms, it is a common scenes; food cannot be spoiled if the Microorganisms does not exist.

\section{Nutrients available for growth}

Which are the nutrients needed for development and multiplication of those microorganism.

\section{Appropriate surrounding factors}

Represent the most important factor for microorganism to survive and develop, it includes the following:
a. Water activity
b. Temperature
c. Oxygen availability
d. $\mathrm{PH}$ value
e. Redox potential.

It is very important to state that, non-availability of these conditions or some of them will not facilitate the microbial growth or will slow it down.

\section{Food storage for a long time in unsuitable conditions}

The food storage for a long period ignoring the appropriate storage conditions, provides an attractive environment for microbial growth, while the objective of food storage is for future consumption at certain intervals, considering the standard conditions of storage, the type and nature of the stored food that Identifies where and how to be kept.

\section{Spoilage appearance as a result of microorganisms growth}

An important point needs to be clarified here, any undesirable
Volume 4 Issue I - 2016

\author{
Samer Alnahass \\ Saudi Arena Aviation Support Services, Saudi Arabia
}

Correspondence: Samer Alnahass, Catering Operations Manager, Saudi Arena Aviation Support Services, Al Rajhi Group, Saudi Arabia,Email samer_alnahass@hotmail.com

Received: February 9, 2016 | Published: February 24, 2016

changes in food odour or color, for most of us, is a clear evidence, of its spoilage. However, many kinds of foods require the cellular activities as a part of its preparation, which will be responsible for the unpleasant odour or color, like in meat or fish pickling.

On the other hand, there are very important changes that are considered a part of product preparation in many kinds of food, like bread or alcoholic drinks. Here it requires the activity of "Saccharomyces cerevisiae", which is a kind of "Yeast" that plays the main role in fermentation facilitating the preparation (Figure 1).

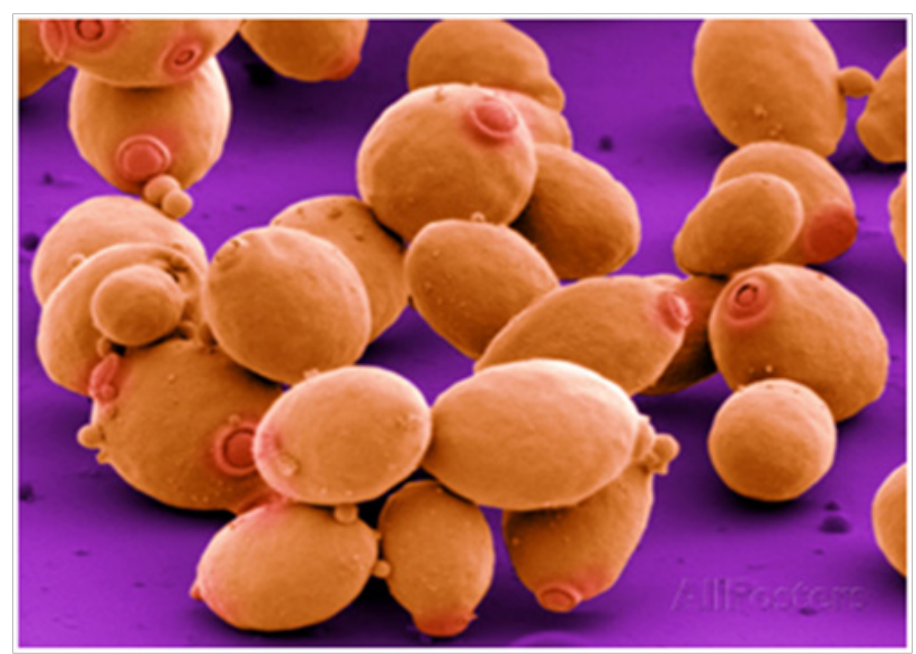

Figure I Saccharomyces cerevisiae.

Another example, in the production of yogurt in the dairy industry, the responsible microorganism kind of bacteria is known as "Lactobacillus bulgaricus".

Therefore, we cannot consider the previous changes as spoilage resulting from the microorganism activities; it is the required activist for food preparation (Figure 2).

In conclusion, food spoilage means that, the original nutritional value, texture, flavour of the food are damaged, and became harmful and non-edible (Figures 3-5). 


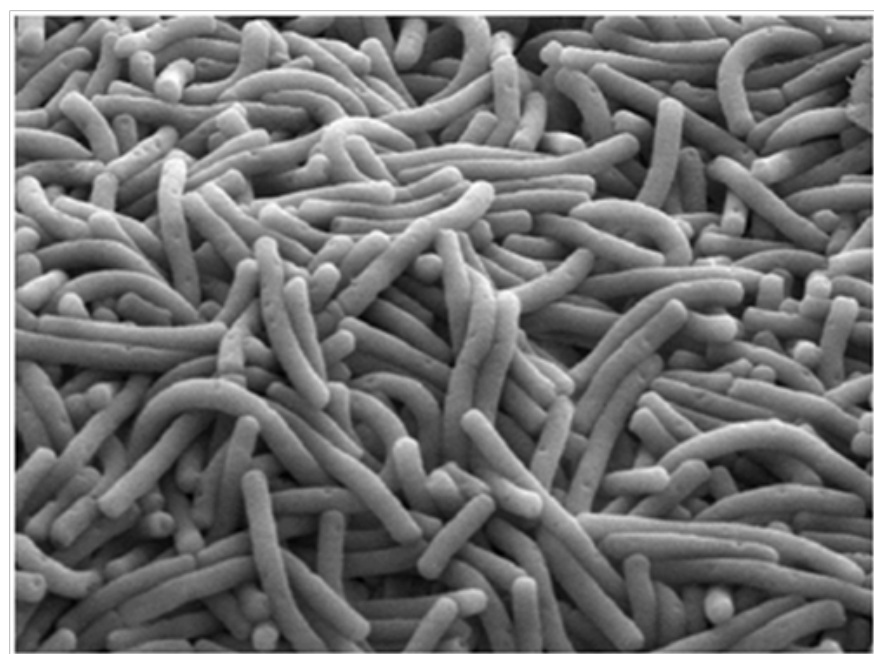

Figure 2 Lactobacillus bulgaricus.

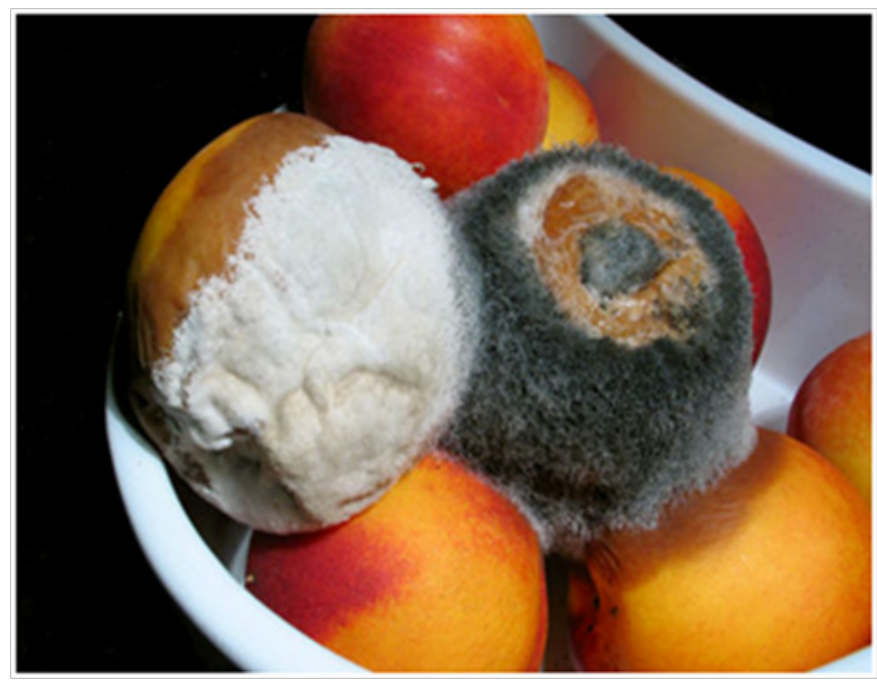

Figure 3 Spoiled fruit by fungi.

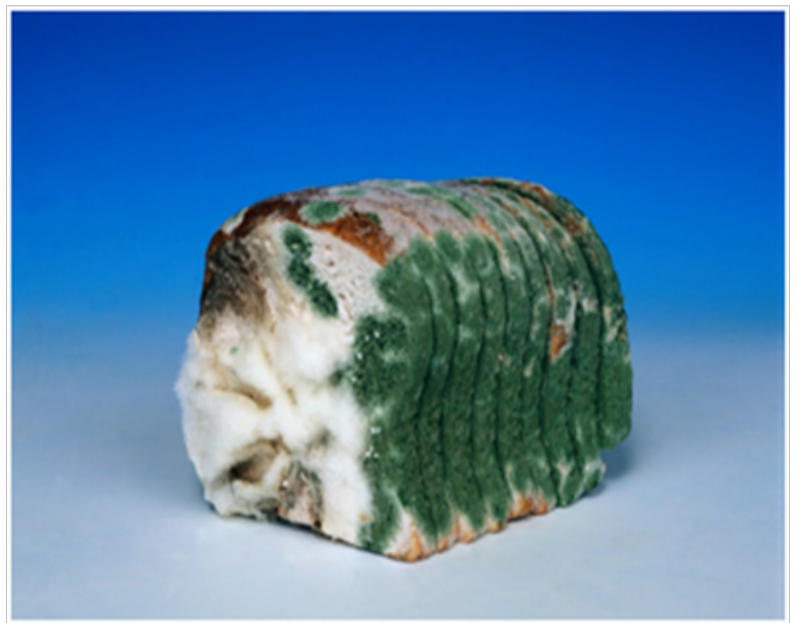

Figure 4 Spoiled bread by fungi.

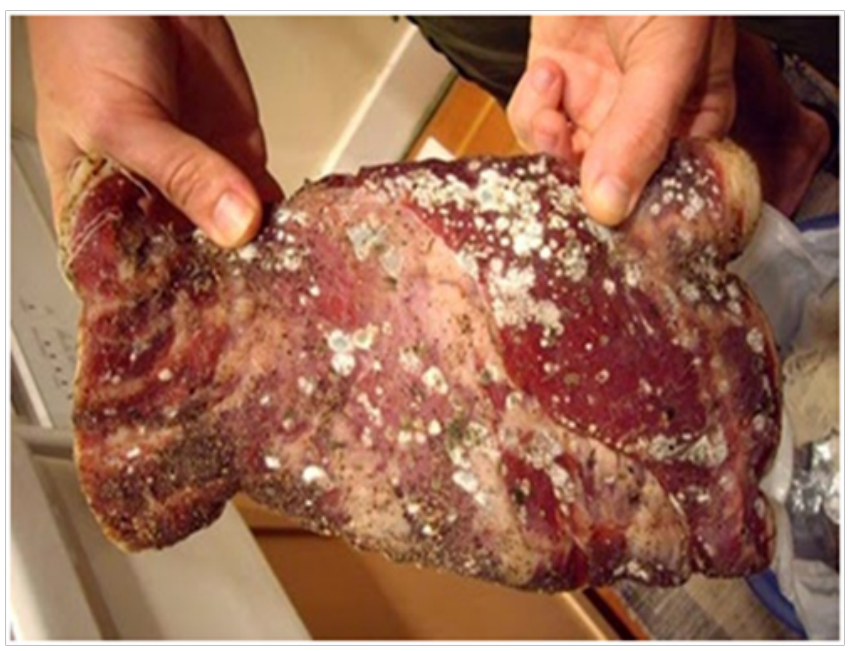

Figure 5 Spoiled meats by bacteria.

\section{Preservation, historical overview}

For food preservation in general, and all the procedures applied to eliminate microbial spoilage since ancient times, there have been three kinds of food preserving:
i. Natural food preservation
ii. Chemical food preservation
iii. Physical preservation

However, those procedures are not enough to sanitize the food or to eliminate germs; the entire role it can perform is to inhibit the microbial growth and activity. The most natural popular procedure used through mankind history is the food drying by using sun rays which is scientifically known as "Dehydration".

Until our present days human being is using this method especially in Africa where the sun is burning and shining all the year round, the temperate is between $42-45 \mathrm{C} 0$, I have personally enjoyed many sorts of food preserved by this method (Figure 6).

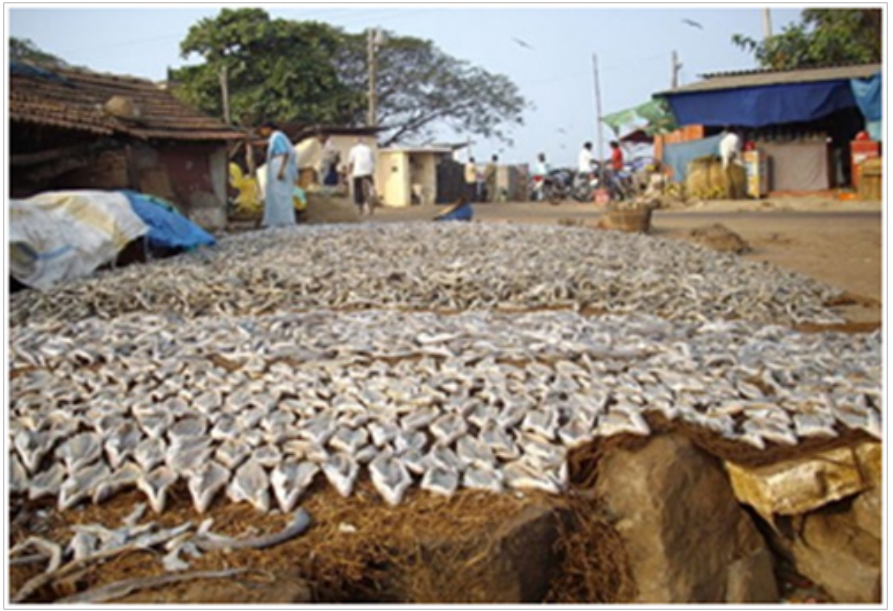

Figure 6 Fish dehydration in India. 


\section{What is dehydration?}

Dehydration in food processing by which many types of food can be preserved for indefinite periods by extracting the moisture, thereby inhibiting the growth of microorganism. Dehydration is one of the oldest methods for food preservation and was used in prehistoric eras in sun-drying seeds Figure 7.

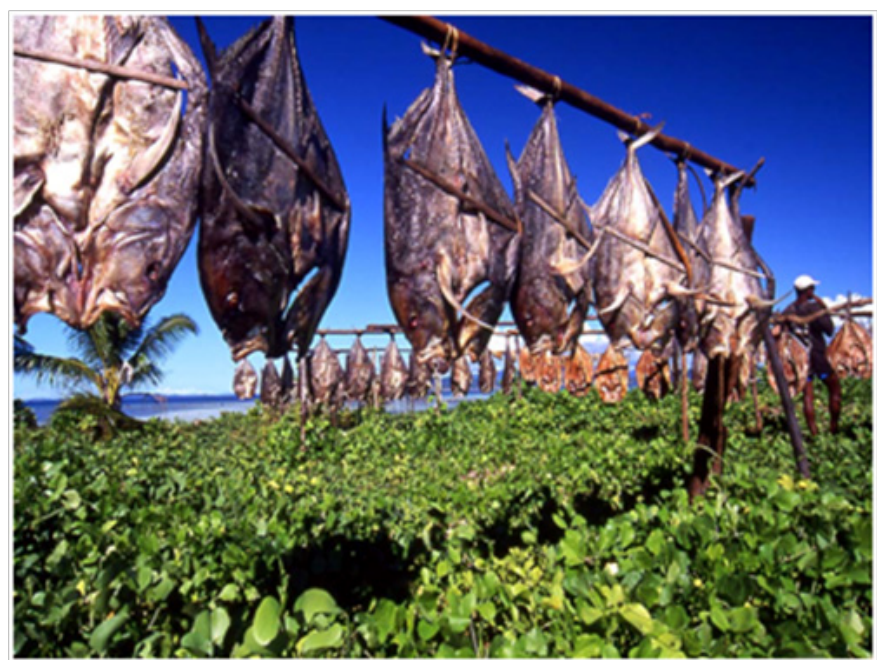

Figure 7 Fish dehydration in isolated islands.

Moreover, human being discovered that he can also preserve his food by using ice to freeze his food by keeping it in very low temperature Figure 8.

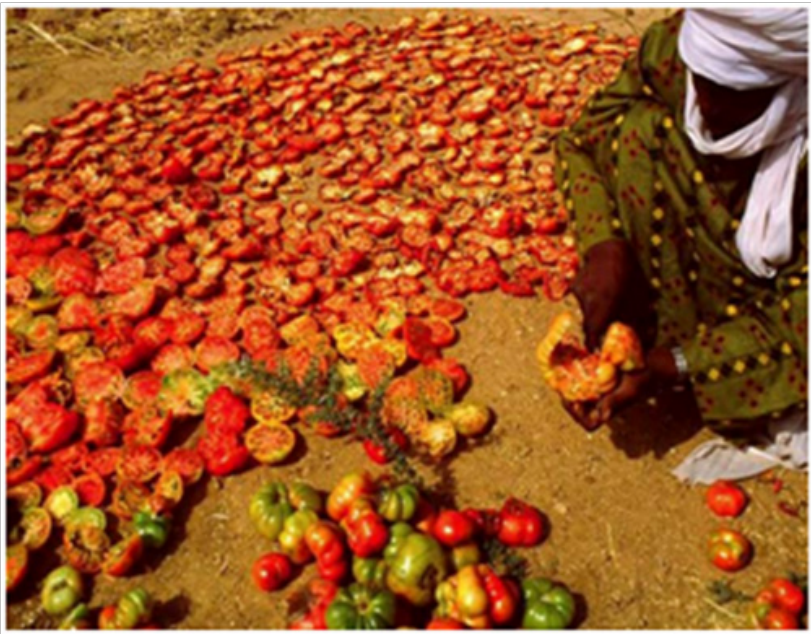

Figure 8 Vegetables dehydration in Africa.

\section{What is freezing?}

Freezing in food processing, method of preserving food by lowering the temperature to inhibit microorganism growth. The method has been used for centuries in cold regions, and a patent was issued in Britain as early as 1842 for freezing food by immersion in an ice and salt brine. It was not, however, until the advent of mechanical refrigeration that the process became widely applicable commercially.

It is worthy to point out that the human being at these periods was able to use some of the surrounding available materials in his environment to preserve his own food, and this was the beginning of the shifting to the usage of chemicals in food preservation.
The first material used as a preservative was the salt or "Sodium Chloride", enabled the early man of fish salting and preserving of meat, developing slightly until to more complex materials such as "Sorbic Acid" and "Sulfur Dioxide", as we will explain later.

Then, with science development by human efforts two main principles have been discovered; "Pasteurization" and "Sterilization" which had the most important great impact in many areas, particularly the Food Preservation Field (Figure 9).
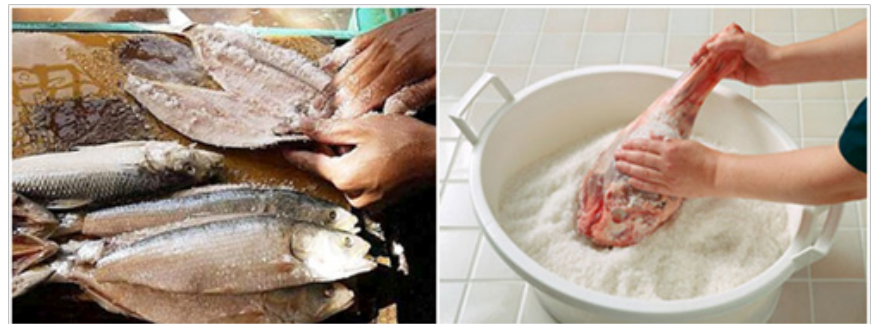

Figure 9 Fish and meat salting.

\section{What is pasteurization?}

Pasteurization, heat-treatment process that destroys pathogenic microorganisms in certain foods and beverage. It is named for the French scientist Louis Pasteur, who in the 1860s demonstrated that abnormal fermentation of wine and beer could be prevented by heating the beverages to about $57^{\circ} \mathrm{C}\left(135^{\circ} \mathrm{F}\right)$ for a few minutes. Pasteurization of milk, widely practiced in several countries, notably the United States, requires temperatures of about $63^{\circ} \mathrm{C}\left(145^{\circ} \mathrm{F}\right)$ maintained for 30 minutes or, alternatively, heating to a higher temperature, $72^{\circ} \mathrm{C}$ $\left(162^{\circ} \mathrm{F}\right.$ ), and holding for 15 seconds (and yet higher temperatures for shorter periods of time).

\section{What is sterilization?}

Sterilization is a technique to prolong the shelf life of foods. In general the food products are heated to 110 to $135^{\circ} \mathrm{C}$ for about 15 to 20 minutes. Some canned products are heated for up to one hour. All micro-organisms are killed during this process. After sterilization the product is free of germs and, if stored correctly, have a shelf life of several years. Unfortunately heat-sensitive vitamins are destroyed for the benefit of a long shelf life. Taste and color of the food are also affected by the heat. Sterilization is used for foods like meat, poultry, vegetables, fruits and milk. During the sterilization of milk for example the process not only kills bacteria and germs. Its taste is considerably changed and important vitamins are destroyed. Furthermore the heat treatment lessens the biological value of the milk proteins (Figure 10).

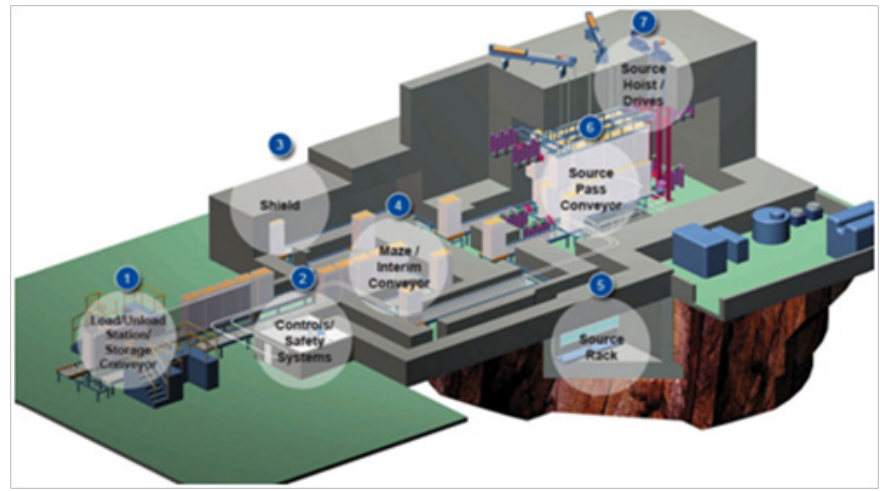

Figure 10 Stages of food irradiation. 
Now days and after this huge step in physics we started to relay in new kind of food preservation called "Food irradiation".

\section{What is food irradiation?}

The application of ionizing radiation to food is a technology that improves the safety and extends the shelf life of foods by reducing or eliminating microorganisms and insects. Like pasteurizing milk and canning fruits and vegetables, irradiation can make food safer for the consumer *FDA.
Irradiations provide its activeness and the results provide that we can apply this method to get the following benefits:

i. Prevention of Food borne Diseases

ii. Preservation

iii. Control of Insects

iv. Delay of Sprouting and Ripening - irradiation can be used to inhibit sprouting (e.g., potatoes) and delay ripening of fruit to increase longevity (Table 1).

Table I Some historical development of the chemical preservers

\begin{tabular}{|c|c|}
\hline Prehistoric & Salt , smoke \\
\hline Ancient Egypt & Vinegar, honey, Oil \\
\hline Ancient Rome & Sulfur dioxide to preserve wine \\
\hline Before I400AD & Pickling, especially for the meat by BEUKELS \\
\hline I775AD & The use of Borax By HOFER \\
\hline $1810 \mathrm{AD}$ & The use of carbon dioxide to preserve meat \\
\hline $1833 \mathrm{AD}$ & The use of Creosote to preserve meat by REICHENBACH \\
\hline I858AD & Discovering the effect of Boric Acid on microorganism by JAQUES \\
\hline I859AD & Sorbic acid extraction from Rawan berry oil by HOFMANN \\
\hline I865AD & Discovering the effect of Formic acid on microorganism by JODIN \\
\hline I874AD & Discovering the effect of Salicylic acid on microorganism by THIERSCH \& KOLBE \\
\hline I875AD & Discovering the of Benzoic acid as anti-microbial effect by FLECK \\
\hline I907AD & Suggestion of using Formaldehyde \& Hydrogen peroxide in diary preservation by BEHRING \\
\hline 1908AD & Approval uses of Benzoic acid in food industry in USA \\
\hline I913AD & Discovering the effect of Para-Chloro-Benzoic acid as anti-microbial effect by MARGOLIUS \\
\hline I923AD & Discovering the effect of Para-Hydroxy-Benzoic Acid Ester as anti-microbial by SABALTISCHKA \\
\hline 1938AD & Suggestion of using Propionic acid in bakery product preservation by HOFMAN, DALBY, SCHWEITZER \\
\hline 1954AD & Production of industrial Sorbic acid in Germany \\
\hline I956AD & Discovering the effect of Estar Carbonic Acid as anti-microbial by GENTH,THOMA, BERNBARD \\
\hline
\end{tabular}

\section{Acknowledgements}

None.

\section{Conflict of interest}

Author declares that there is no conflict of interest. 